\title{
Study on the feasibility of classified cultivation for master majoring in precision optical engineering
}

Feng Shi, Ci Song, Ye Tian, Guipeng Tie, Junfeng Liu, et al.

Feng Shi, Ci Song, Ye Tian, Guipeng Tie, Junfeng Liu, Hang Xiao, "Study on the feasibility of classified cultivation for master majoring in precision optical engineering," Proc. SPIE 11143, Fifteenth Conference on Education and Training in Optics and Photonics: ETOP 2019, 111433B (2 July 2019); doi: $10.1117 / 12.2523625$

SPIE Event: Fifteenth Conference on Education and Training in Optics and Photonics: ETOP 2019, 2019, Quebec City, Quebec, Canada 


\title{
Study on the feasibility of classified cultivation for master majoring in precision optical engineering
}

\author{
Feng Shi ${ }^{\text {a, b, c }}$, Ci Songa, b, c,*, Ye Tian, ${ }^{\text {a, b, c }}$, Guipeng Tie ${ }^{\text {a, b, c }}$, Junfeng Liu ${ }^{\text {a, b, c }}$, Hang Xiao ${ }^{\text {a, b, c, d }}$ \\ ${ }^{a}$ College of Intelligent Science and Technology, National University of Defense Technology, \\ Changsha, 410073, China \\ ${ }^{b}$ Hunan Key Laboratory of Ultra-Precision Machining Technology, Changsha, 410073, China \\ ${ }^{\circ}$ Laboratory of Science and Technology on Integrated Logistics Support, National University of \\ Defense Technology, Changsha, 410073, China \\ ${ }^{\mathrm{d}}$ College of mechanical and electrical engineering, Changsha University, Changsha, 410003, \\ China
}

\begin{abstract}
With the expansion of military master and the adjustment of military scale structure, new requirements have been put forward for talent cultivation, especially for the high-level applied talents cultivation. Talents with different specifications, types and levels must be cultivated in the education process. Therefore, the master cultivation mode needs to be explored and improved. This paper systematically studies the classification standards, training scheme, graduation standards in the classification cultivation mode for master majoring in precision optical engineering, as well as the feasibility and implementation suggestions of the classification cultivation for master in military academy. By means of field investigations, collection and arrangement of network resources, questionnaire survey of characteristic samples, and combining with data resources of master, the sample database is established by collecting relevant data including professional types, training scheme, dissertation quality, professional development prospects and post applicability to output talents. The results indicate that the quality of graduate training can be effectively improved by the classifying training mode of "academic" and "applied". The classified cultivation can not only satisfy the reform and development trend of military academy and the diversified demands of modern war for military talents, but also provide reference for high-level innovative military talents cultivation.
\end{abstract}

Keywords: Classified cultivation, precision optical engineering, military academy

\section{INTRODUCTION}

For a long time, cultivation of graduate students of comprehensive military universities mainly paid attention to their academic ability, concentered on the curriculum design, teaching mode, and graduate evaluation, but insufficiently focused on classified cultivation to the students combined with their individual differences according to the military progress of science and technology development, which cannot reflect the different requirement to various military units. As a result, the monotony of cultivating mode and the homogeneity of the students led to the saturation of academic person in military institutes and universities ${ }^{[1]}$. On the other hand, it leads to the shortage of applied personnel who are familiar with application and maintenance of high-tech weapons and equipment in frontline troops. With the passage of time, contradiction caused by the cultivation has become increasingly prominent, resulting in the waste of talents as well as dislocated use of talent. Meanwhile, Postgraduates exported by comprehensive military universities have to put more time and effort for secondary learning after entering into work on basic theory and professional knowledge. Therefore, exploring classified cultivation mode may be benefit to the cost reduction of personnel training and utilization, which has extensive and far-reaching military benefits and brings huge social benefits.

With the rapid development of the world economy, community has more diversified and specific demands for talents. This puts forward higher requirements for talent cultivation in institutes and universities, which means that the traditional mode of single academic talent cultivation cannot satisfy the current social requirements. Meanwhile, for university graduates, the lack of professional knowledge and practical experience is conflicted with employer's requirements for talent. This phenomenon makes the employment of university students more serious. Subjectively, difficulty on 
graduate's employment is mainly caused by the lack of understanding of social needs, professional knowledge, practical experience, employment concept and employment psychology on students. Objectively, social public opinion, government policy, family education, university training mode and other factors also affect graduate's employment, especially the defect of university talent cultivation mode. In this background, the classified cultivation of qualified personnel is presented for the reformation of talents cultivation mode, which develop teaching methods and cultivation models base on the respect of student's individual differences, considering the current social demand, combining with student's characteristics as well as career plans, for the purpose of cultivating professional talents with qualified skills to meet the demand of various industries.

The talent cultivation mode in Chinese colleges and universities usually includes general talent training mode and special talent training mode. The former pays attention to the basic, comprehensive content and the universality of the training mode, while the latter focuses on the training of specialized disciplines, aiming at the systematic and in-depth training of specialized talents in a certain discipline. Such a training mode is likely to result in the students' lack of characteristics in scientific and technological skills, poor innovation ability, and weak social adaptability, which contradicts the diversified needs of the society ${ }^{[2-4]}$. The mode of talent classification training should be based on the rational guidance of students' career planning and the premise of students' scientific and reasonable self-cognition and choice. For this requirement, the establishment of a scientific and reasonable selection guidance system becomes the key to the correct operation of the classification training mode, and the reasonable and accurate classification selection is the prerequisite for the implementation of the classification training mode. In general, as the higher education become more and more popular, colleges and universities continue to increase enrollment and scale, greatly improving school construction and student training. However, there are many challenges in the development of talent skills and educational quality.

\section{MODE OF CLASSIFIED CULTIVATION}

In comprehensive military institutes and universities, classified cultivation mode need to be extensively analyzed and studied due to the lack of mature experience to the mode. However, classified training between local universities and military universities is similar in terms of objectives and contents from a macro perspective. The specific implementation methods of military universities is the aspect that need to be consider. In the implementation of the classified training system, not only the training objectives and programs of the classified cultivation should be formulated from the macro level, but also the academic and applied curriculum system should be re-established from the micro level, and the specific construction of each course should be implemented.

\subsection{Classification criteria}

The classification criteria can be considered from the following aspects. First, in the form of entrance examination, it should be composed of the qualifications of students and the form of entrance examination. The former determines the basic qualities of the students enrolled in the relevant majors, while the latter combines the students' own volunteers. At the same time, it is suggested that the training objectives and methods should be clearly stated in the form of entrance examination so as to make the students fully understand. Second, in the process of classification, it needs the participation of experts in relevant fields and industries. The expert group should be composed of student instructors and experts from outside schools or even enterprises in corresponding fields. Specifically, the recommender of academic postgraduate should be a Postgraduate Tutor with high academic influence in this field, while the employment instructor or the person in charge of the corresponding job should be responsible for the recommendation of applied postgraduate. Thirdly, the students should provide relevant information about their own self-evaluation as a reference for classification. Specifically, in the way of selecting examination, improving the examination form[5]. Generally, the examination is divided into "professional knowledge examination" and "retest" links. Based on the above analysis, the weight of the "comprehensive re-examination" results are increased appropriately. This form of examination can increase the standardization and scientific of the entrance examination for postgraduates. Applied graduate exam in the professional examination should reduce the proportion of the study, and focus on the professional degree graduate to the comprehensive quality and practical ability.

\subsection{Training programs}

At present, postgraduate curriculum system of china is generally operated according to the discipline type, which is suitable to academic postgraduate students, but not fit to the cultivation objective of application-oriented postgraduate students. Employing classified cultivation, it is necessary to add the practical education in the application-oriented postgraduate cultivation for the purposes of strengthening practical ability and scientific research ability as well as 
promoting understanding and application of the course content to students. In the classified cultivation, all courses should be divided into theoretical foundation courses and thematic practice courses. The modules of thematic practice courses are divided according to the frontiers of science and technology in the practice process, so that students can choose different modules according to their work requirements. The advantages of modular curriculum system are the characteristics of flexibility, practicality and frontier, in which the number and structure of modules can be adjusted according to the actual situation.

In National University of Defense Technology of China, most of practical learning are an auxiliary form of classroom teaching, and the content design is relatively specific and single. So, improving the practical teaching environment is essential as well as building a multi-level and diversified practices and innovative teaching system. Due to the problems of traditional practice teaching contents and methods ignoring the innovation ability training and lacking practical ability training, it are necessary that increasing scientific research innovation ability training to academic talents and engineering practice training to application-oriented talents, enlarging practice teaching credits proportion (accounting for $30 \%$ of the total credits) as well as construction of university-enterprise collaboration in education, with the results of stimulating students' innovation consciousness and improving the ability of engineering practice effectively. Make a research to the training mechanism of practical innovation ability for different types of talents. Meanwhile, differentiated practical courses are set up combining the goals of practical ability to different type talents with increasing the proportion of practical teaching credits. Concretely, academic or research-oriented students are provided with training such as basic scientific research and innovative design, so as to increase the training of scientific research and innovation ability. The practical courses of mechanical equipment development, manufacturing and application are offered to students of compound application type. Relying on the practical teaching bases inside and outside the university and the schoolenterprise cooperation laboratory, the practical teaching focusing on production practice and engineering application is carried out for the cultivation of engineering application ability of student.

\subsection{Construction of cultivation environment}

In order to improve the existing practical teaching environment and build a practical and innovative teaching system with multi-level and diversified characteristic, it can support the construction of practical teaching platform with independent courses, incorporating the courses into the applied postgraduate teaching curriculum system which is the same important as the classroom theoretical teaching. Meanwhile, qualification of faculty, sufficient practical teaching facilities and abundant practical teaching hours should be ensured to effective implementation of practical teaching. Take the major of mechanical engineering as example, the applied graduate students should be cultivated with understanding of various related research directions within the framework of mechanical engineering and disciplines, so as to grasp broad knowledge and adaptability. Therefore, the construction of practical teaching platform should reflect comprehensiveness, strengthen the training and improvement of various modern experimental methods and skills for application-oriented postgraduates, but also cultivate students' practical innovation ability.

Team construction and teaching guidance method reformation are also important to improve the teaching quality. In order to improve the pertinence of guidance and promote academic exchange between different teachers, a researchoriented and application-oriented guidance team can be set up with complementary advantages. In the concrete implementation, the "dual tutor system" in the mode of co-training can be referred. To the research-oriented students, the responsible tutor and the tutor team guidance are adopted, and the school guidance tutor and the enterprise guidance tutor responsibility system are adopted for the application-oriented students. Compare with the traditional teaching methods, classified training needs more work from teachers. Therefore, it is necessary to clarify the responsibilities and obligations of teachers, at the same time, to increase rewards for the classified teachers, and giving a scientific and reasonable evaluation and encouragement to the teacher's input in the whole classification teaching process, and encouraging the teacher to participate better in the guidance work of the classification training.

\subsection{Graduation Standards}

Assessment mechanism of classified cultivation should be constructed in diversify. Establish a combination of internal and external teaching quality evaluation system. In detail, besides a management evaluation system of university, it also need to establish a multi-faceted teaching quality evaluation system contained students, mentor teams, and society. Only in the open evaluation mode of internal and external interaction, the advantages of classified training will be put into effect, and a talent classification training model will be formed that adapts to social development and takes into account the individual characteristics of students. Over the years, under the influence of emphasizing academic over education, most postgraduate training of China have adopted degree thesis as an evaluation method for degree assessment. For 
academic graduate students who are oriented towards scientific research, writing a dissertation will undoubtedly play a role in improving the knowledge structure and the level of scientific research. However, this assessment form is not effective for the quality assessment of applied graduate students. Under the background of talent training diversification, it is necessary to establish a set of multi-degree assessment mechanism that is suitable for it. It is suggested that the academic dissertation evaluation mechanism should still be employed in the academic training mode to reflect the discipline theory system. For applied graduate students, the assessment should be emphasized to the practical ability and operational ability of students. The forms of assessment should be advocated with strong application and creativity, such as research reports, planning plans, design plans, original works, and et al. In addition, a completed mid-term assessment mechanism should be established. The mid-term assessment system is an important part of postgraduate quality control. In the postgraduate assessment mechanism, the mid-term and the final degree assessment should have equal important. The mid-term assessment can achieve the purpose of elimination and selection, which can not only guarantee the overall quality of graduate students, but also enable some of the outstanding master students to enter the doctoral stage in advance through the system, and promote the formation of two types of graduate student training mechanism.

\section{RESEARCH AND ANALYSIS OF POSTGRADUATE TRAINING MODES IN DOMESTIC UNIVERSITIES AND RESEARCH INSTITUTIONS}

\subsection{Analysis of the cultivation mode of Harbin Institute of Technology of China}

Harbin Institute of Technology established the postgraduate training mode, and formulated the "Comprehensive reform plan of education of Harbin Institute of Technology" to carry out the educational reform from the aspects of educational concept, training mode and optimizing the curriculum system. The reform is aim to improve the quality of graduate education, establish an integrated undergraduate and postgraduate curriculum system, highlight the cultivation of innovative ability of postgraduates, and distinguish degree level and degree type in consideration of the curriculum system and teaching content of graduate and postgraduate students. The training for academic postgraduates is to improve their innovation abilities, combined training mode for academic masters and doctors. While, the cultivation of graduate students in professional degree focus on the capacities for specific vocations, cultivating their comprehensive qualities, referring university-enterprise joint training mode, emphasizing student's practice ability and entrepreneurial ability. From a comprehensive perspective, the training program reflects the characteristics of the discipline, highlights the personalized training, and realizes its training objectives and basic requirements for the degree on the basis of course learning, scientific experiments and paper research.

Fig. 1 shows the cultivation system of Harbin Institute of Technology, in which the platform courses include foreign language, mathematical basis, quality improvement (including research methods, academic writing and norms, innovation, professional ethics, professional quality and cultural accomplishment). Students are allowed to choose postgraduate courses as their personalized development courses at the postgraduate stage (10 credits), and the professional courses of master students such as English courses, core courses and elective courses can be reserved for credit recognition at the postgraduate stage. Postgraduate students can take core professional courses and elective professional courses from colleges, and record them into credits. Doctoral students can choose core subject courses of master students as their degree courses, or choose graduate courses of other majors as their elective courses. 


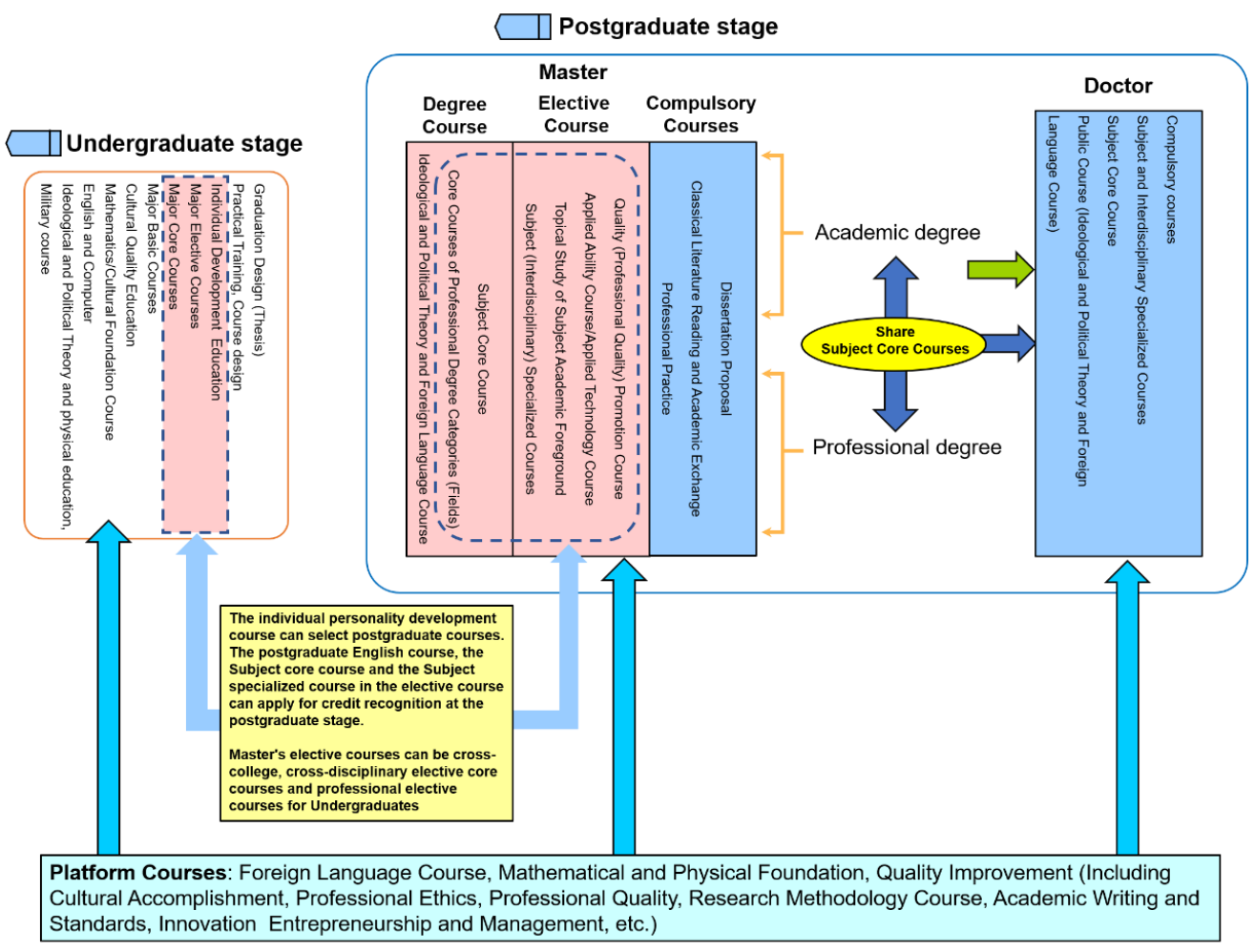

Fig.1 Schematic diagram of the cultivation system of master and doctor

The credit requirements of master and doctor training in Harbin Institute of Technology is shown in figure 2.

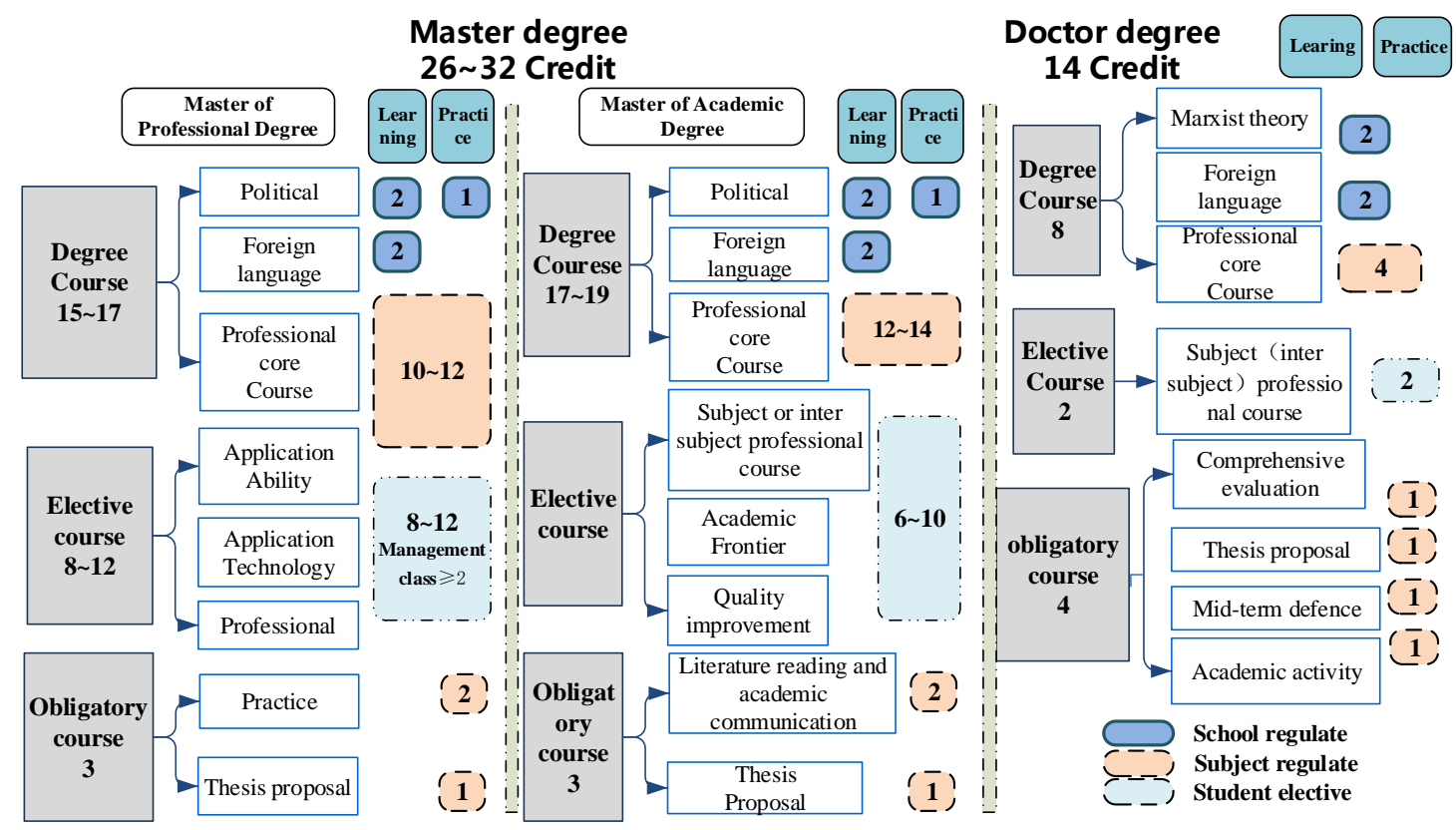

Fig.2 Schematic diagram of credit setting scheme for postgraduate education

Fig. 2 indicate that stipulated that 26 and 32 credits are requested for master cultivation as well as 14 credits for the doctor training. From the further analysis of the training mode, it can be seen that Harbin Institute of Technology focuses on the cultivation and long-term development of graduate students' innovation and entrepreneurship ability. Course installation refers to the similar subject of the high-level university from home and board. Bases on different levels and different types of graduate student training goal, determines its knowledge structure and the basic ability. On this basis, 
the curriculum of academic degree, professional degree, master degree, doctor degree, successive master and doctor degree is determined, respectively. In order to borrow the experience of high-level universities at home and abroad in graduate teaching, Harbin Institute of Technology First-level claim that the disciplines with doctoral degrees are required to cooperate with international high-level scholars, and build 1 to 3 first-level mater degree courses. Meanwhile, the assessment of each lecturer put in an important status to the university construction. Course construction and teaching achievements of postgraduate, workload and quality evaluation results will be included in the important assessment indexes of the new round of classified post appointment for teachers. Teacher's support of course construction and teaching reform projects on postgraduates should be increased. Teachers who have made important contributions in curriculum construction and teaching reform will be commended and given preferential policy support.

\subsection{Teaching reform of Nankai University of China}

Nankai University has been experimenting classified cultivation on postgraduate students since 2008 , which is divided into courses and research type. The former is committed to adapting to the market demand, improving students' ability to analyze and solve practical problems. The research type is committed to improving scientific research ability of students. In the first academic year, research students enter the pre-doctoral course study and arrange appropriate scientific research work after completing the course tasks and passing the examination. When the academic performance and research ability of the course meet the requirements, the qualification of doctoral degree will be obtained in the third year. If the relevant ability does not meet the requirements, students can complete the required credits of graduate courses in the third year, and obtain the master's degree after accomplishment of master's thesis defense. The postgraduate students in courses type should complete the study of basic theories and professional courses in the first year, then focus on practical application and case-based teaching as well as professional practice in the second year. The topic of the master's degree thesis in the course type focuses on the study of practical problems and puts forward solutions. The assessment focuses on the ability of students to analyze and solve practical problems. To the research type of postgraduates, the method of enrollment and admission remains unchanged. In the first year, they should complete public compulsory courses, professional compulsory courses and major elective courses in accordance with the provisions of the training program. At the end of the second semester, students applying for master's degree in research will be evaluated and screened. The third and fourth semesters begin the classified training. In the end of the fourth semester, postgraduate students who pass the course and show good academic research potential will be officially qualified as doctoral students.

\subsection{Cultivation mode reform of Dalian University of Technology of China}

Since 2009, Dalian University of Technology has implemented the reform of classified cultivation in some college. The program of academic master degree focuses on cultivating students' ability to engage in scientific research work, which lays a foundation for their future doctoral studies or academic research work. Applied master focus on engineering technology or management and other practical ability training and improvement. The training of academic postgraduates focuses on the study of basic theoretical knowledge, increases the credit of degree courses and theoretical courses. The training of applied postgraduates focuses on the study of applied technology, and increases the basic courses of applied technology. In terms of dissertation, dissertation of academic master requires certain theoretical depth, difficulty and innovation, while applied master focus on completing specific engineering design and practical projects. Students of academic master degree can apply for continuous study of master and doctoral degree or study for doctoral degree in advance, while students of applied master need to obtain the qualification for doctoral degree by taking entrance examination, or they can get the qualification for doctoral degree by studying for doctoral degree in advance after adjusting the cultivation mode.

\subsection{Practical experience of classified cultivation in universities at home and abroad}

Harbin Institute of Technology, as the first university for the comprehensive reform of professional degree graduate education to the ministry of education of china, takes the lead in exploring and implementing graduate student classified training, which is characterized by exploring ways to cultivate leading engineering and technology talents. Overall, current classified cultivation of postgraduate in China's education teaching management level still has gaps comparing with some western countries such as America famous universities. For example, in the enrollment proportion of the applied postgraduate and academic postgraduate student, admissions proportion of the applied postgraduate is above 55\% in Harvard University each year. The cultivation of postgraduate students is aim to the direct use of knowledge, not on innovative research as the goal, and graduation thesis is not required. In the faculty setting, there are at least three faculty members, such as the faculty at MIT, there are two faculty members and one expert from enterprise or university. The proportion of professional research time in academic postgraduates is large, and the thesis requires the depth of 
academic research, while the practical work experience and solving ability of engineering cases are emphasized by the applied postgraduate students, and the thesis requires the applicability of engineering application. In Russia, the proportion of practical courses and vocational courses in universities is relatively high, focusing on the cultivation of students' vocational skills and practical ability. In the national university of Singapore and Nanyang technological university, specialty and enrollment rules are set up according to the market demand, and tailor-made applicationoriented talents for enterprises, forming an "order-type" training pattern. Correspondingly, enterprises guarantee talent training by internship bases and bonuses. In addition, some European universities pay attention to the design of interdisciplinary curriculum system, so that students can grow up in the interdisciplinary academic or applied research atmosphere.

\section{CONCLUSIONS}

In a word, classified cultivation must carry out with the goal of student-centered. Personnel training is the foundation for the survival and development of university. higher education must take the development of students as the center in meeting the needs of society at the same time. University students hope that the training mode of schools should meet the both needs of their personality development and the needs of career development from the perspective of student development, which requires universities to fully implement the concept of student-oriented education and diversify the training of students. In the view of improving learning interest and learning effect, according to students' personal wishes, learning goals, learning ability and level, university need to determine different training goals, organize different levels of learning content, adopt different educational measures and methods, and implement the differential incentive system, so that the potential of different types of students are fully utilized, which help to stimulate their interest in learning and active learning enthusiasm, and improve the learning effect.

Nowadays, the classification of graduate students that according to the "academic" and "application-oriented" model training has become a trend with the advent of popular education. "Academic postgraduate students" may adopt the traditional degree authorization audit management method, but "Applied postgraduate students" needs to establish a practice-oriented curriculum system by the training unit according to their own characteristics, training ability and local economic development. The aim of "the academic students" is to train personnel engaged in academic research, focusing on the cultivation of innovative consciousness and research ability, and the goal of "the applied students" is to develop knowledge based on social and economic development, focusing on strengthening curriculum learning and practical training.

\section{REFERENCES}

[1] Wang, L., Zhang H., Cheng C. L., "Problems of Classified Cultivation of Postgraduates in the Ten-year Practice of Chinese Universities and Countermeasures," Journal of Heilongjiang College of Education,35(1):4-6(2016).

[2] Qi H.B,. "Research on classified cultivation of military academy graduates," Journal of Naval University of Engineering, 13(1):29-33(2016).

[3] Yao X. P., Hu R. D., "Research on the formation and realization of the talent classified cultivation system in Chinese universities," Education Exploration,11:56-59(2015).

[4] Yuan Q.K., Cheng S. Y., Luo S. M., "Mechanical Engineering Graduate Innovation Ability and Practice Programs," Machine Tool \&Hydraulics,42(16):11-13(2014).

[5] Yan T., Zhao W. C., "Exploration and Practice of Graduate Classification Training System," The Guide of Science \& Education, 166-167(2012). 